\title{
Hyperlalia: a Right Cerebral Hemisphere Syndrome
}

\author{
ATSUSHI YAMADORI, YUKIO OSUMI, MASAYASU TABUCHI, \\ ETSURO MORI, TAKASHI YOSHIDA, SHINGO OHKAWA and \\ YUKIHIRO YONEDA
}

Neurology Service, Hyogo Brain and Heart Center at Himeji, 520 Saisho-Ko, Himeji, Hyogo-Ken, 670, Japan

\begin{abstract}
We describe a new right hemispheric behavioural syndrome for which we propose the name "hyperlalia". In a typical case an apparently unconcerned and expressionless patient is easily prompted to remarkable volubility with a content which is loose and incoherent. The voice is low and monotonous. All the lesions confirmed by computed tomography of the brain overlapped in the perisylvian area in the territory of the right middle cerebral artery.

Loss of a subtle balance between the left hemispheric speech area and the corresponding area in the right hemisphere caused by acute damage of the right perisylvian area may have resulted in disinhibition of the speech function. Similarities and dissimilarities with the known pathology of talkativeness are also discussed.
\end{abstract}

\section{Introduction}

Many types of behavioural change have been described in patients with right hemisphere damage. These include anosognosia with a left hemiparesis (Babinski, 1914), left unilateral spatial neglect (Brain, 1941), difficulty of performing spatiomanual tasks (Paterson et al., 1944), motor impersistence (Fisher, 1956), indifference to surroundings (Gainotti, 1969), musical impairment (Damasio et al., 1977), and difficulties in identifying complex pictorial representations (Warrington, 1985). One important feature common to these symptoms is that they are nonlinguistic, which has been regarded as a hallmark of the right hemisphere syndrome.

However it has become increasingly clear that the right hemisphere also is concerned with language. For instance, Ross found that the right hemisphere has an important role in mediating prosodic aspects of speech (Ross, 1985). Gardner and colleagues have pointed out that the right hemisphere is indispensable for controlling pragmatic use of language (Weylman et al., 1988). We have previously reported excessive writing in right hemisphere damaged patients (Yamadori et al., 1986).

In this type of hypergraphia patients tended to show a strong inclination to write down whatever ideas came into their minds. The resultant script was usually incomprehensible but correct linguistically. Orthography included careless errors such as addition and/or omission of strokes or confusion of spatial arrangement. We interpreted this overwriting tendency as disinhibition of the left hemisphere's linguistic activity from right hemispheric control. 
If this hypothesis is correct, one might expect a similar type of linguistic overactivity in verbal domain. Indeed, Kaneko et al. (1984) reported that volubility was often encountered in a group of patients who had undergone operation for hypertensive hemorrhage in the right hemisphere.

We have been able to confirm the occurrence of a similar disturbance in the acute stage of the right hemisphere stroke, for which we propose the term hyperlalia.

\section{Patients}

Among the patients admitted to the neurology department for the treatment of acute stroke from 1982 to 1987 we found 11 patients whose behaviour was characterized by prominent talkativeness. Criteria of selection was not quantitative and was based on personal impression by one of the authors (A.Y.). However it may be of interest to note that retrospective review of nurse's charts revealed that attending nurses were also aware of this behaviour.

Of the 11 patients six were males and five were females. All were right handed. Their age ranged from 45 years to 77 years old with a mean of 68.9 years. All patients had a left hemiparesis, left hemi-sensory deficit, constructional impairment and flattening of emotion to various degrees (see Table 1).

All received Folstein's Mini-Mental State Examination (Folstein et al., 1975 ) slightly modified for Japanese patients' use. The highest score was 24 and the lowest 16 with a mean of 21.8. No case showed signs of aphasia or apraxia.

TABLE 1. The clinical features of the 11 patients with hyperlalia

\begin{tabular}{ccccccccccccccc}
\hline Case & Age & Sex & Hand & $P$ & $S$ & $A$ & $H H$ & USN & CI & An & $H G$ & MMT & $\begin{array}{c}\text { Duration } \\
\text { (month) }\end{array}$ \\
\hline 1 & 72 & M & R & + & + & - & - & + & + & + & + & 23 & 1.5 \\
2 & 67 & M & R & + & + & - & - & + & + & - & + & 23 & 1.0 \\
3 & 74 & M & R & + & + & - & - & - & + & + & + & 21 & 2.5 \\
4 & 45 & M & R & + & + & - & + & + & + & + & - & 22 & $\frac{3}{3}$ \\
5 & 73 & F & R & + & + & - & + & + & + & + & - & 16 & $\frac{3}{1}$ \\
6 & 72 & F & R & + & + & - & + & + & + & + & - & 22 & 1.5 \\
7 & 77 & F & R & + & + & - & + & + & + & + & - & 22 & 3 \\
8 & 72 & F & R & + & + & - & + & + & + & - & - & 23 & $\frac{2}{2}$ \\
9 & 67 & F & R & + & + & - & + & + & + & + & - & 22 & 3 \\
10 & 66 & M & R & + & + & - & + & + & + & - & - & 24 & $\frac{3}{1}$ \\
11 & 73 & M & R & + & + & - & + & + & + & + & - & 22 & $\frac{1}{1}$ \\
\hline
\end{tabular}

M, male; F, female; Hand, handedness; $R$, right handedness; $P$, left hemiparesis; $S$, left sided sensory deficit; A, aphasia; HH, left homonymous hemianopia; USN, left unilateral spatial neglect; CI, constructional impairment; An, anosognosia for left hemiparesis; HG, hypergraphia; MMT, score of Mini-Mental State Test (full score: 30). Persistence of hyperlalia throughout the hospital stay is indicated by underlining in the duration column. 

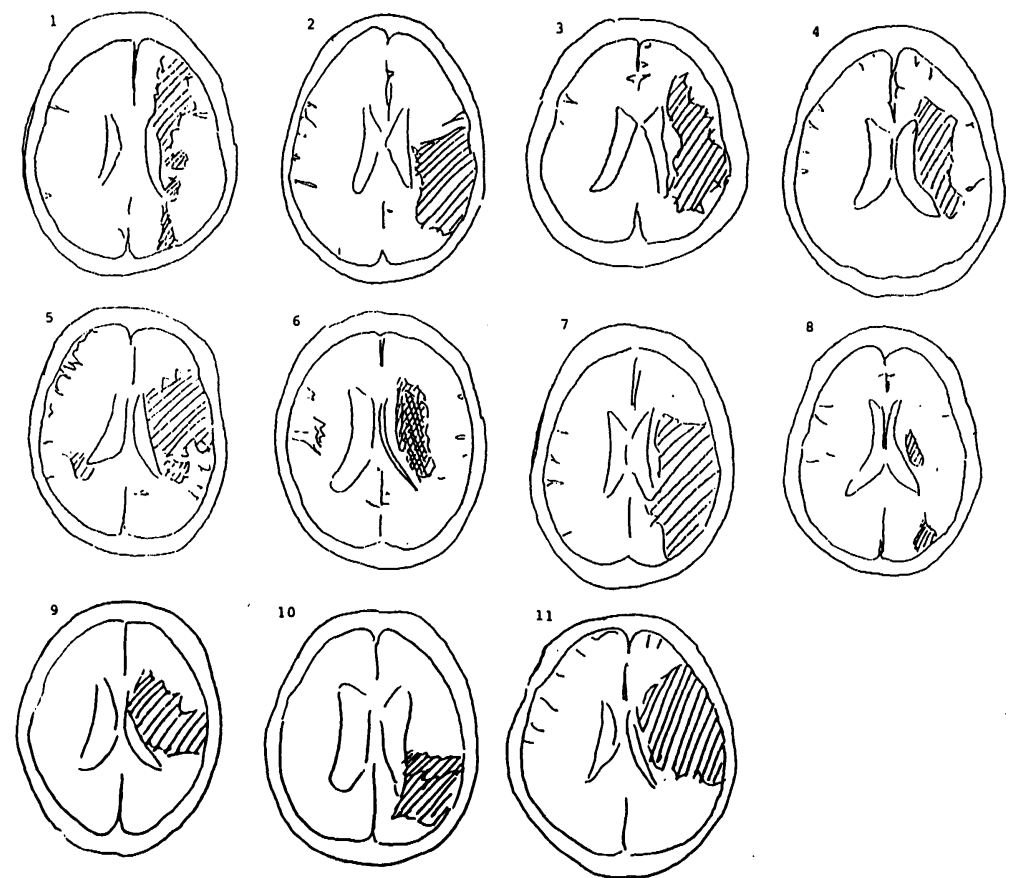

FIG. 1. Schematic representation of CT lesions in all the cases of hyperlalia at approximately the same level just above the basal ganglia. Number represents case number as summarized in Table 1 .

All patients had had a stroke (ten infarcts and one hemorrhage). All lesions detected by CT scans conformed to the territory of the right middle cerebral artery. A substantial portion of the centrum semiovale was involved in all cases except case 8 whose lesion was smaller on CT imaging. All lesions were situated in the perisylvian area.

\section{Illustrative Cases}

\section{Case 10 (T.K.)}

A 66-year-old right handed male and an owner of a book store suddenly developed left sided weakness and was brought into the neurology service of Hyogo Brain and Heart Center at Himeji on 7 December, 1982. On admission neurological examination revealed conjugate deviation of the eyes to the right, left sided hemiparesis including the face and tongue, sensory deficit on the left side of the body and left homonymous hemianopia. There was a left Babinski sign. A brain CT revealed a low density area in the posterior portion of the territory of the right middle cerebral artery involving the parieto-temporal region. Arteriography revealed delayed 


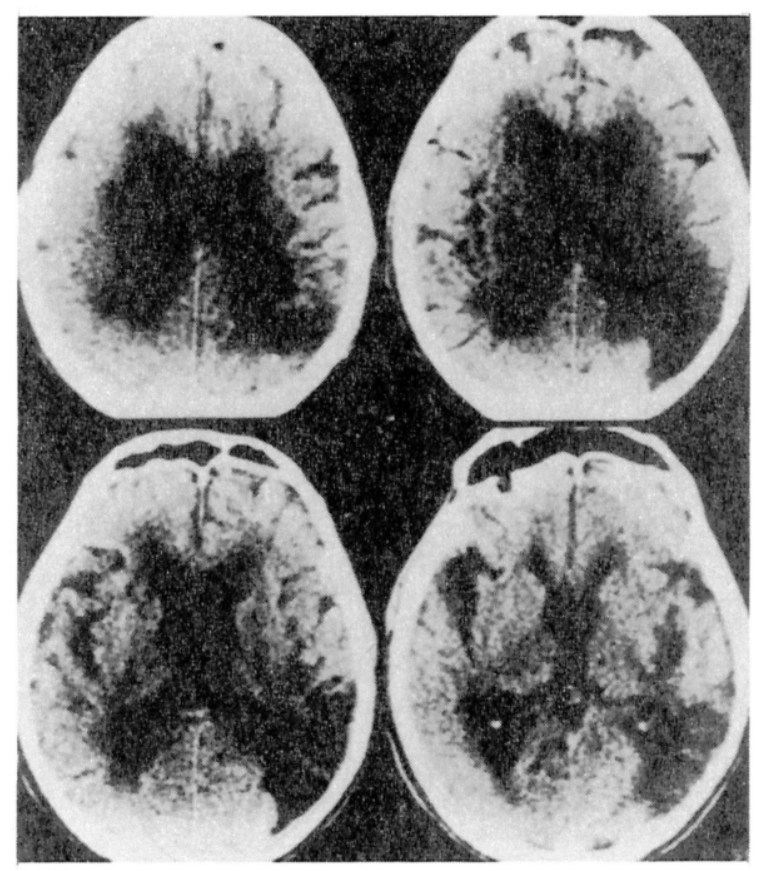

FIG. 2. Computed tomography of the brain of case 10. Low density area is apparent in the posterior portion of the right temporo-parietal region.

perfusion of frontal and rolandic branches of the right middle cerebral artery territory but no stenotic lesion was present.

On neuropsychological evaluation he was awake and responsive but was indifferent to his surroundings. He was oriented in time and place. $\mathrm{He}$ remembered correctly what had happened to him. He could remember three words after $5 \mathrm{~min}$. He showed left unilateral spatial neglect on the linebisection and line-cancellation tests. He could not copy a cube correctly and the left side of the model was ignored. Topographical orientation was normal. He showed no aphasia or apraxia. The score on Mini-Mental State Examination on the second hospital day was 24 (full score 30).

Immediately after admission his volubility was apparent to everyone around him. During the medical examination and psychological testing he talked incessantly unless asked to stop. Talk was usually initiated by prompting. He would start by answering appropriately to a question but would soon change topics in unexpected directions. The content of speech was not particularly abnormal but was often irrelevant to the situation. $\mathrm{He}$ was not agitated. His speech was monotonous and the voice low.

During his admission the left hemiparesis improved considerably. On hospital day 16 unilateral spatial neglect as judged by line-cancellation and line-bisection test had disappeared but copying of a cube was still difficult. Talkativeness was still prominent at the end of the first month when he was 
discharged home. According to his family he had not been a particularly talkative man before his strokes.

\section{Case 3 (S.M.)}

A 74-year-old right handed man developed left sided weakness and was brought to the neurology service of Hyogo Brain and Heart Center at Himeji on 3 September, 1987. On admission he was drowsy and confused. Neurological examination revealed conjugate deviation of the eyes to the right, a right sided grasp reaction, dysarthria, left hemiparesis including the face and tongue and severe left sided hemi-sensory deficit. The deep tendon reflexes were normal. A computer tomography of the brain revealed a low density area in the right fronto-parieto-temporal region consistent with an infarct in the territory of the right middle cerebral artery but sparing lenticulostriate branches. Carotid arteriography revealed occlusion of the right middle cerebral artery at its Ml portion but sufficient collateral circulation was present via the right anterior cerebral artery.

On the sixth hospital day it was found that he had a left anosognosia. He denied he had any motor weakness and when shown his paralysed left hand, he stated that it did not belong to him but to his physician. He believed that his left leg belonged to another physician. He went on talking about these

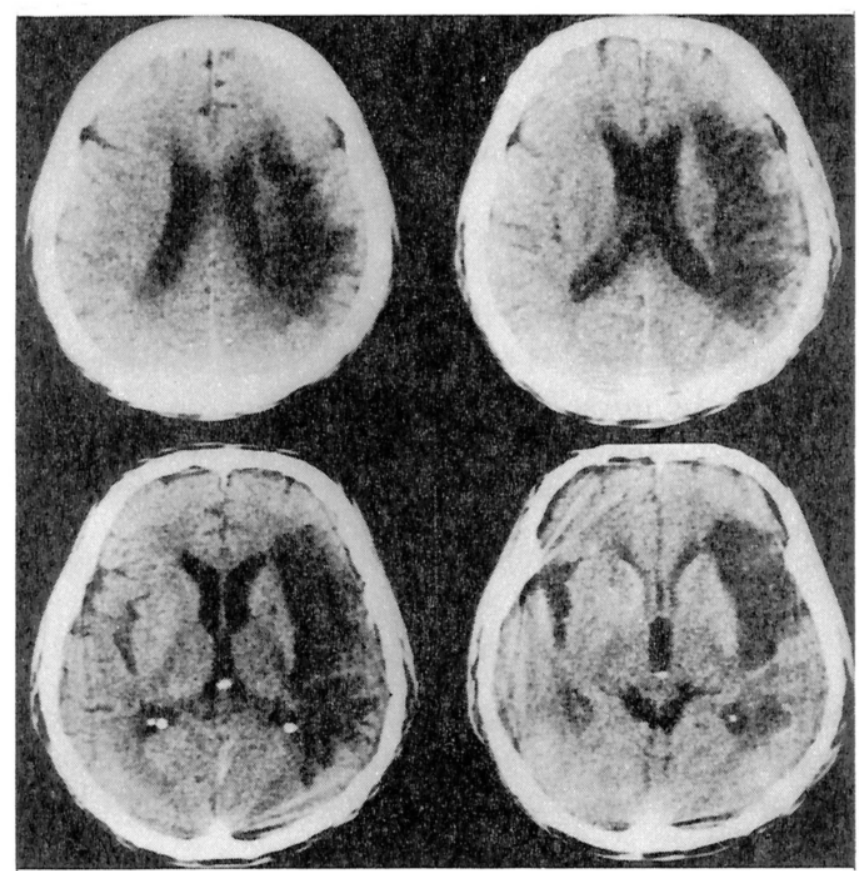

Fig. 3. Computed tomography of the brain of case 3. Infarction includes extended area of the territory of the right middle cerebral artery sparing the territory of the lenticulostriate branches. 
bizarre experiences without showing the slightest sign of embarrassment. It soon became clear that this talkativeness was not confined to anosognostic topics.

Neuropsychological examination on hospital day 50 revealed he was disoriented in time. Digit span was 6 forward. Only two of three names were recalled after $5 \mathrm{~min}$ and constructional difficulty was marked. He had no left unilateral spatial neglect on the line-bisection test and there was no aphasia or apraxia. He remained garrulous and hypergraphic. He jotted down irrelevant things on sheets of paper during the physical examination. Anosognosia had disappeared. His face remained expressionless and the voice low and monotonous.

He was discharged home on hospital day 82 when he was still talkative. According to his wife he had been a man of few words.

\section{Nature of Talkativeness}

Talkativeness in these cases occurred on a similar behavioural background. All the patients were apathetic and unconcerned about their surroundings or their own physical condition. The face remained expressionless suggesting depression. However, when they were spoken to, they revealed a remarkable tendency toward volubility. If appropriate interlocutory remarks or confirmatory nodding were used by the doctor, conversation could be maintained almost indefinitely. Despite this it was quite easy for them to stop talking once they were asked to do so.

The content of speech was often loose and the topic of conversation easily strayed into an irrelevant direction. Also the content could be easily influenced by suggestion. In some instances speech was unrealistic and confabulatory.

In all cases the voice was low and the manner of talking monotonous which led in some instances to a misunderstanding that patients were indulging in a monologue rather than conversing. However, monologue was observed especially at night. Thus 10 of 11 patients were heard talking to themselves during the nurse's night round.

The duration of talkativeness varied. In five cases it subsided within 2 months after the onset of stroke while in the other six remaining cases it was still noticeable at the discharge point of 1 to 3 months.

\section{Discussion}

To our knowledge, this unique verbal behaviour characterized by an increase in output, its inductive nature and its looseness of content associated with personal and environmental lack of concern has not been described in its proper perspective.

Of course talkativeness occupies an important place in several well established clinical syndromes and differentiation from these is necessary.

In mania talkativeness occurs with euphoria, hyperactivity and flight of 
ideas (American Psychiatric Association, 1987), while in hyperlalia talkativeness is seen with apathy and indifference.

Pressure of speech occasionally occurs at the outset of Wernicke's aphasia (Albert et al., 1981). Patients may talk incessantly making communication impossible. Loss of comprehension capacity as well as apparent degradation of verbal output into jargon indicates its aphasic nature.

Patients with Wernicke-Korsakoff syndrome due to bilateral basal frontal lesions are occasionally very voluble. Shallow euphoria and a tendency toward confabulation may be conspicuous. Although these features were also seen in some of our present series severe amnesia and disorientation as seen in Korsakoff's patients was absent.

Confusional states are common in the acute stage of stroke affecting the territory of the right middle cerebral artery (Mesulam et al., 1976; Mori et al., 1987). In the present series 10 of the 11 patients obtained the MMSE score of 23 or less which was the cutting line for confusion by our criteria (Mori et al., 1987). The remaining one (case 10) scored 24. Acute agitated delirium in which affective and autonomic excitation are seen also follows right middle cerebral artery strokes (Caplan et al., 1986; Mori et al., 1987). Talkativeness may occasionally occur in delirium (Schmidley et al., 1984; Fisher et al., 1983). None of the present patients showed signs of agitation or hyperactivity. Thus talkativeness could be a sign of a confusional state but it does not necessarily mean that the patient is in a state of agitated delirium.

All the lesions conformed to the territory of the right middle cerebral artery and involved the perisylvian area. This location corresponds to the so called language area of the opposite left hemisphere (Benson, 1979). This strategic location of lesion site led us to the following speculation about the pathophysiology of hyperlalia.

A concept of rivalry between the two hemispheres at a perceptual level was first postulated by Denny-Brown et al. (1952) and later applied to spatial attention by Kinsbourne (1977). According to his theory spatial attention is maintained by a dynamic equilibrium between the two cerebral hemispheres. Each hemisphere has a tendency to orient its attention toward the contralateral external space. With damage in the right hemisphere orienting tendency toward the right which is intrinsic to the left hemisphere occurs causing left sided unilateral spatial neglect. With damage in the left hemisphere the right hemisphere takes over attentive activity uncovering an orienting tendency toward the left external space. But since the right hemispheric orienting gradient toward the left space is much less prominent than the left hemispheric tendency toward the right one, resultant orientation bias is less conspicuous than with left unilateral spatial neglect.

This type of hemispheric rivalry may also be at work in language function but the two hemispheres may not compete at the same level. Most linguistic activities are powerfully lateralized to the left hemisphere in the right handed population. But the right hemisphere also has its share of linguistic function. For example, capacities like comprehension of connotative aspects of language (Winner, 1977), comprehension of linguistic information at the paragraphic level or construction of a consistent narration out of several 
sentences have been attributed to the right hemisphere (Weylman et al., 1988) and would be consistent with our own clinical experience with right brain damaged patients (Yamadori, 1989). The right hemisphere seems to possess a certain regulatory function for placing the left hemispheric linguistic activity into a broad and proper contextual frame.

When the right hemisphere sustains damage acutely, the left hemisphere is released from this regulatory function. Coupled with a decrease in cognitive function a patient could easily be tipped into a state of semiautomatic linguistic activity. In such a state slight linguistic prompting like greeting or questioning might easily trigger a verbal response. Once triggered, the left hemisphere would be further activated by its own verbal activity resulting in continuous talking.

Deprived of right hemispheric control narration tends to be guided more by literal meaning than by implicative meaning resulting in incoherent output. Hyperlalia can be understood therefore as a manifestation of disinhibited left hemisphere speech activity and not as a heightening of inner drive to express oneself.

Weinstein, summarizing his important studies on changes of verbal behaviour in right hemisphere damaged patients including disorientation, reduplication, nonaphasic misnaming and anosognosia, speculated that the right hemisphere is more specialized for the experiential aspects of language and implied a possible role of cortico-limbic circuitry in mediating this function (Weinstein et al., 1977). However, we suspect the presence of hyperlalic tendency, i.e. easy reactivity of autonomic linguistic system, behind these verbal activities. In this regard it is quite interesting to note that anosognosia is a phenomenon elicitable only by verbal prompting (Frederiks, 1963; Weinstein et al., 1977). Our experience suggests that anosognosic patients are often very talkative. In fact eight of the present series showed anosognosia.

Right hemispheric hypergraphia may be produced by a similar mechanism (Yamadori et al., 1986). Originally we had expected hypergraphia and hyperlalia should occur simultaneously. In fact none of the five hypergraphic patients in the previous report was hyperlalic. In the present series only three of 11 patients demonstrated hypergraphia. This indicates a subtle but substantial difference in the production of these two states of increased linguistic output. Whether this is due to the difference of lesion distribution or difference in some other qualitative mechanism is unknown.

In the present series all patients had constructional impairments and all but one patient showed left unilateral spatial neglect.

\section{References}

Albert, M. L., Goodglass, H., Helm, N. A., Rubens, A. B. and Alexander, M. P. (1981). "Clinical Aspects of Dysphasia". Springer-Verlag, Wien.

American Psychiatric Association (1987) Quick Reference to the Diagnostic Criteria from DSM-III-R. pp 125-126.

Babinski, M. J. (1914). Contribution a l'étude des troubles mentaux dans l'hemiplegie organique cérébrale (anosognosie). Revue Neurologique, 27, 845-848.

Benson, D. F. (1979). "Aphasia, Alexia and Agraphia". Churchill, New York. 
Brain, R. (1941). Visual disorientation with special reference to lesions of the right cerebral hemisphere. Brain, 64, 244-272.

Caplan, L. R., Kelly, M., Kase, C. S., Hier, D. B., White, J. L., Tatemichi, T., Mohr, J., Price, T. and Wolf, P. (1986). Infarcts of the inferior division of the right middle cerebral artery: Mirror image of Wernicke's aphasia. Neurology, 36, 1015-1020.

Damasio, R. A. and Damasio, H. (1977). Musical faculty and cerebral dominance. In "Music and the Brain". (Eds M. Critchley and R. A. Henson). William Heinemann, London, pp 141-155.

Denny-Brown, D., Meyer, J. S. and Horenstein, S. (1952). The significance of perceptual rivalry resulting from parietal lesion. Brain, 75, 433-471.

Fisher, C. M. (1956). Left hemiplegia and motor impersistence. Journal of Nervous and Mental Disease, 123, 201-218.

Fisher, C. M. (1983). Abulia minor and agitated behavior. Clinical Neurosurgery, 31, 9-31.

Folstein, M. F., Folstein, S. E. and McHugh, P. R. (1975). "Mini-Mental State". A practical method for grading the cognitive state of patients for the clinician. Fournal of Psychiatric Research, 12, 189-198.

Frederiks, J. A. M. (1963). Anosognosie et hemiasomatognosie. Revue Neurologique, 109, 585597.

Gainotti, G. (1969). Reactions “catastrophiques" et manifestations d'indifference au cours des atteintes cérébrales. Neuropsychologia, 8, 379-384.

Kaneko, M. and Tanaka, T. (1984). Long term prognosis of surgically treated cerebral hemorrhage. Japanese Journal of Stroke, 6, 52-53. (in Japanese).

Kinsbourne, M. (1977). Hemi-neglect and hemisphere rivalry. In "Advances in Neurology, Vol. 18: Hemi-Inattention and Hemisphere Specialization". (Eds E. A. Weinstein and R. P. Friedland). Raven, New York, pp 41-47.

Lipowski, Z. J. (1987). Delirium (Acute confusional state). Fournal of the American Medical Association, 258, 1789-1792.

Mesulam, M-M., Waxman, S. G. and Geschwind, N. (1976). Acute confusional state with right middle cerebral infarction. Journal of Neurology, Neurosurgery and Psychiatry, 39, 84-89.

Mori, E. and Yamadori, A. (1987). Acute confusional state and acute agitated delirium. Occurrence after infarction in the right middle cerebral artery territory. Archives of Neurology, 44, 1139-1143.

Paterson, A. and Zangwill, O. L. (1944). Disorders of visual space perception associated with lesions of the right cerebral hemisphere. Brain, 67, 331-358.

Ross, E. D. (1985). Modulation of affect and nonverbal communication by the right hemisphere. In "Principles of Behavioral Neurology". (Ed. M-M. Mesulam). Davis, Philadelphia, pp 239-257.

Schmidley, J. and Messing, R. (1984). Agitated and confusional states in patients with right hemisphere infarctions. Stroke, 15, 883-885.

Warrington, E. K. (1985) Agnosia: the impairment of object recognition. In "Handbook of Clinical Neurology. Vol. 1. Clinical Neuropsychology". (Ed. J. A. M. Frederiks). Elsevier, Amsterdam, pp. 333-349.

Weinstein, E. A. and Friedland, R. P. (1977). Behavioural disorders associated with hemiinattention. In "Advances in Neurology, Vol. 18: Hemi-Inattention and Hemisphere Specialization". (Eds E. A. Weinstein and R. P. Friedland). Raven, New York, pp 5162.

Weylman, S. T., Brownell, H. H. and Gardner, H. (1988). "It's what you mean, not what you say": pragmatic language use in brain-damaged patients. In "Language, Communication and the Brain". (Ed F. Plum). Raven, New York, pp 229-243.

Winner, E. and Gardner, H. (1977). The comprehension of metaphor in brain-damaged patients. Brain, 100, 717-729.

Yamadori, A., Mori, E., Tabuchi, M., Kudo, Y. and Mitani, Y. (1986). Hypergraphia: a right hemisphere syndrome. Journal of Neurology, Neurosurgery and Psychiatry, 49, 11601164.

Yamadori, A. (1989). Language and the right hemisphere. Higher Brain Function Research, 9, 155-162. (in Japanese). 


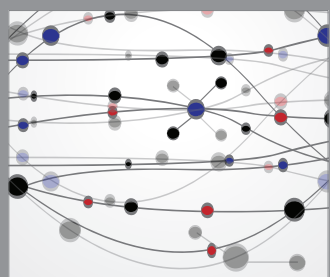

The Scientific World Journal
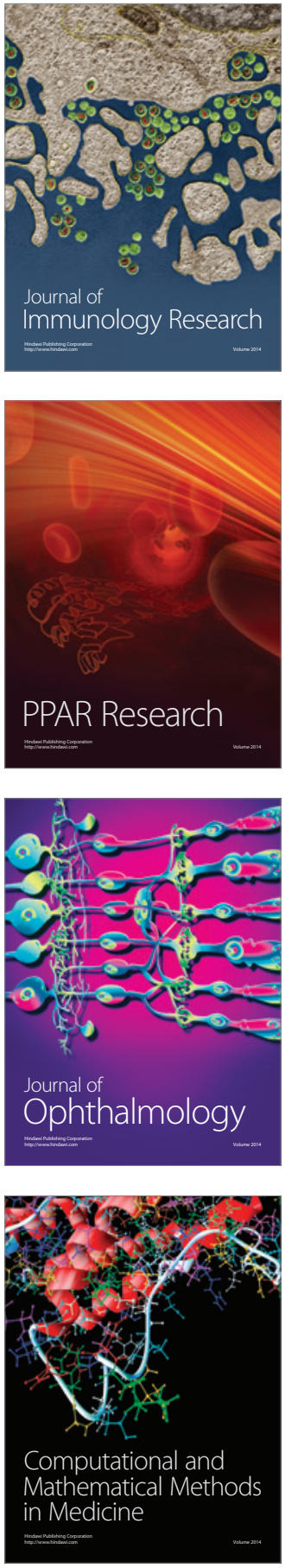

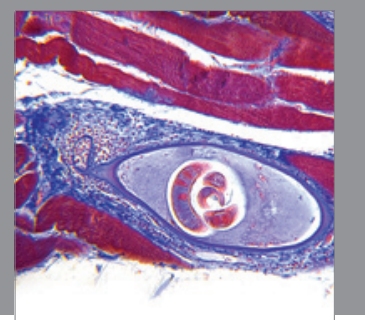

Gastroenterology

Research and Practice
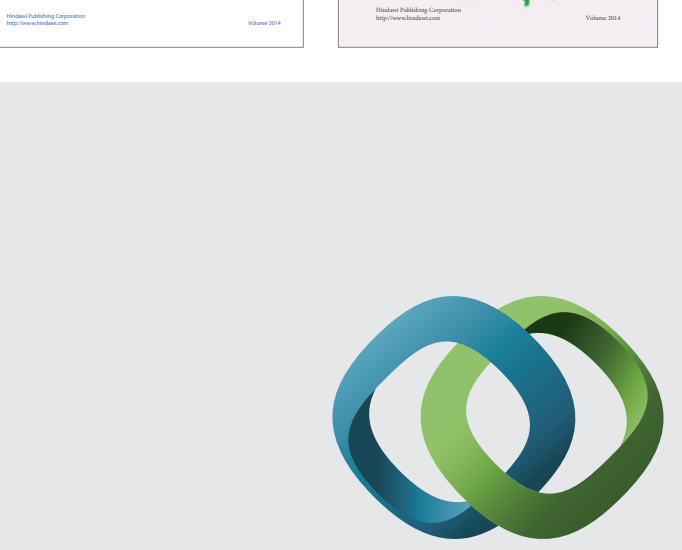

\section{Hindawi}

Submit your manuscripts at

http://www.hindawi.com
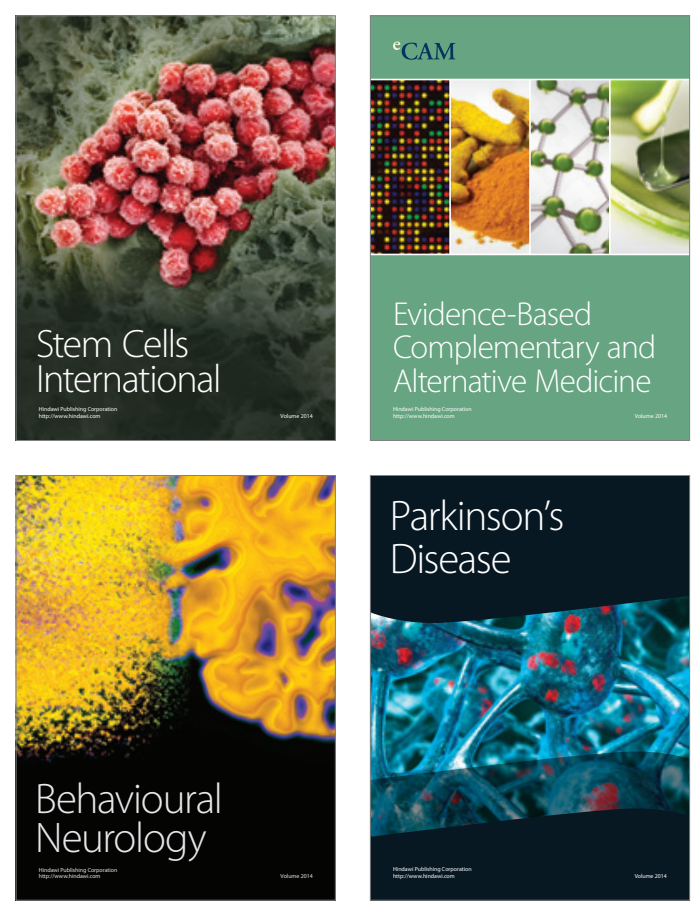

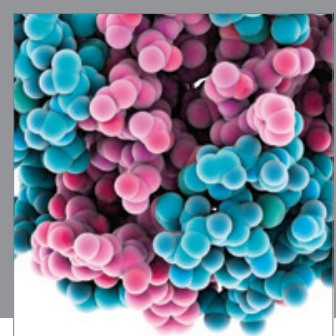

Journal of
Diabetes Research

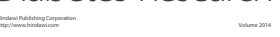

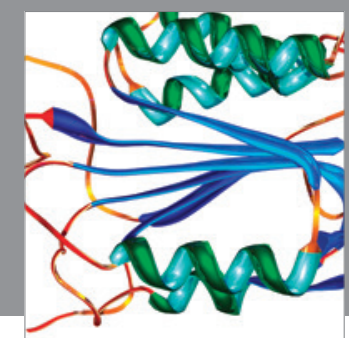

Disease Markers
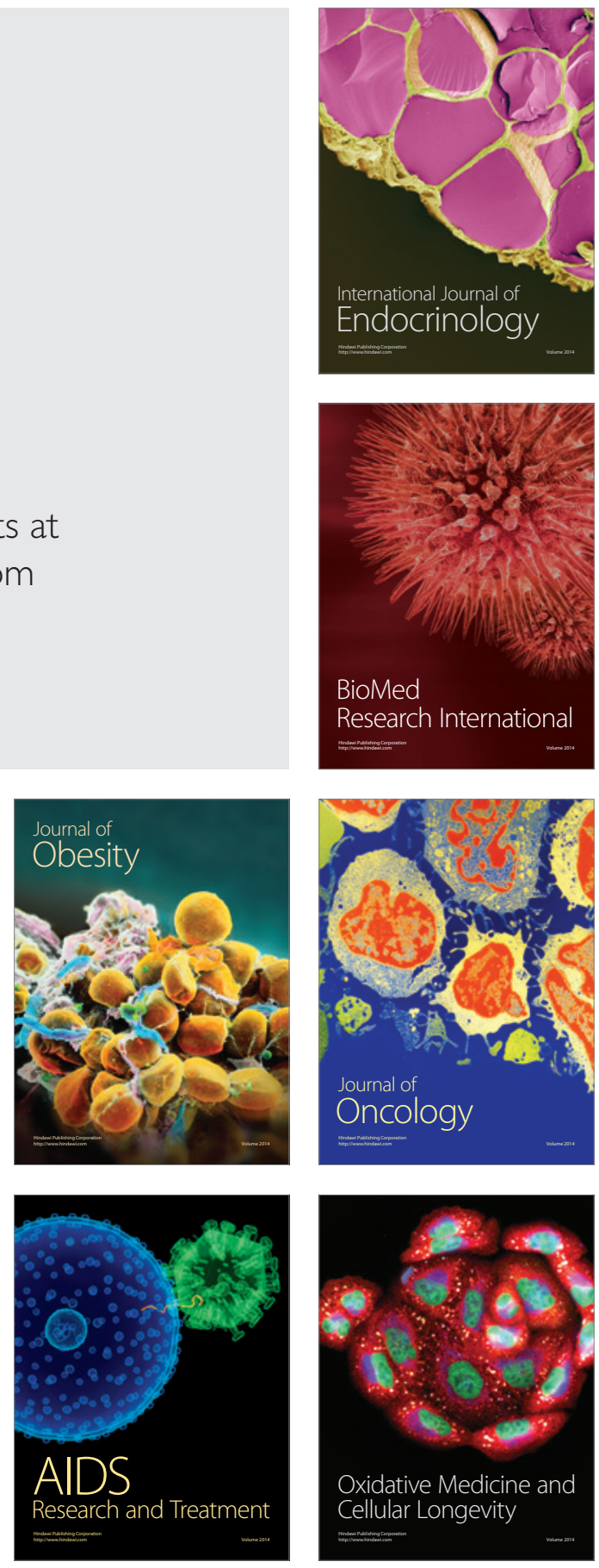